\title{
Verkehrsschutz im englischen Privatrecht
}

Zur Beständigkeit von Erwerbsvorgängen nach englischem Sachen-, Stellvertretungs-, Abtretungs- und Bereicherungsrecht

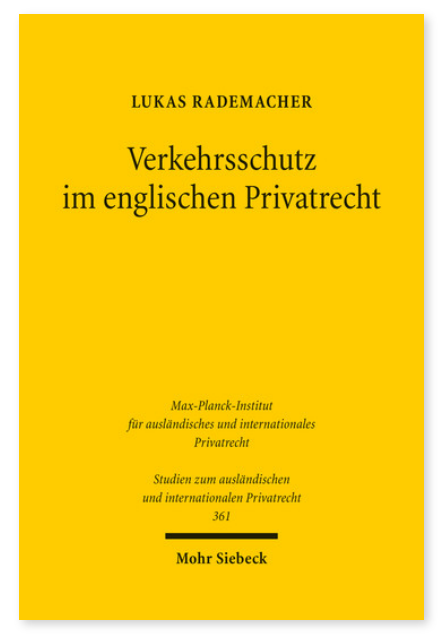

2016. XVI, 286 Seiten. StudIPR 361

ISBN 978-3-16-154880-2

DOI 10.1628/978-3-16-154880-2

eBook PDF 79,00€

ISBN 978-3-16-154865-9

fadengeheftete Broschur 79,00€
Im deutschen Eigentums-, Stellvertretungs-, Abtretungs- und Bereicherungsrecht gilt in unterschiedlichem Maße der Verkehrsschutzgedanke. Danach soll der Erwerb einer Rechtsposition grundsätzlich unabhängig sein von den Beziehungen zwischen dem Vertragspartner des Erwerbers und Dritten. Inwieweit lässt sich auch im englischen Recht ein allgemeines Verkehrsschutzprinzip identifizieren? Mit diesem Ansatz behandelt Lukas Rademacher aus vergleichender Perspektive übergreifende Fragen der ansonsten zumeist unverbundenen Rechtsgebiete contract, property, tort, unjust enrichment und trust - jeweils zusätzlich durchzogen von der bis heute lebendigen gedanklichen Parallelität von common law im engeren Sinne und equity. Dabei stellen die aus der deutschen Diskussion bekannten Problemfelder das Gerüst bereit, anhand dessen das englische Recht entfaltet wird. Dies ermöglicht einen unmittelbar vergleichenden Zugriff auf die jeweils zugrunde liegenden Wertungen.

Lukas Rademacher Geboren 1981; Studium der Rechtswissenschaften in Düsseldorf (Erste Juristische Prüfung) und Oxford (Magister Juris); Referendariat und Zweites Staatsexamen in Düsseldorf; Wissenschaftlicher Mitarbeiter am Institut für Rechtsgeschichte in Münster; dort 2016 Promotion; derzeit Wissenschaftlicher Mitarbeiter am Institut für internationales und ausländisches Privatrecht in Köln.
Jetzt bestellen:

https://mohrsiebeck.com/buch/verkehrsschutz-im-englischen-privatrecht-9783161548802?no_cache=1 order@mohrsiebeck.com

Telefon: +49 (0)7071-923-17

Telefax: +49(0)7071-51104 